\title{
The effect of high hydrostatic pressure acclimation on acute temperature tolerance and phospholipid fatty acid composition in the shallow-water shrimp Palaemon varians
}

\author{
Alastair Brown $^{\mathrm{a}, *}$, Sven Thatje ${ }^{\mathrm{a}}$, Alejandro Martinez ${ }^{\mathrm{a}}$, David Pond ${ }^{\mathrm{b}}$, Andrew Oliphant ${ }^{\mathrm{a}}$ \\ ${ }^{a}$ Ocean and Earth Science, University of Southampton, National Oceanography Centre Southampton, European Way, Southampton SO14 $3 Z$ H, UK \\ ${ }^{\mathrm{b}}$ Scottish Association for Marine Science, Oban, Argyll PA37 1QA, UK
}

\section{A R T I C L E I N F O}

\section{Keywords:}

Adaptation

Caridea

$\mathrm{CT}_{\text {max }}$

Deep sea

Ecology

Physiology

\begin{abstract}
A B S T R A C T
Extant deep-sea fauna, including hydrothermal vent endemics such as bresiliid shrimp, are descended from shallow-water ancestors. Previous studies have demonstrated the capacity of shallow-water shrimp to acclimate to hydrostatic pressure representative of the vent environment. It has been proposed that this hyperbaric acclimation depends in part on shifts in phospholipid fatty acid composition to maintain biomembrane function. These shifts are also predicted to reduce critical temperature tolerance, potentially limiting the possibility of direct colonisation of the hydrothermal vent environment. Here, we present evidence that acclimation to high hydrostatic pressure $\left(10 \mathrm{MPa} \approx 1000 \mathrm{~m}\right.$ water depth) decreases acute temperature tolerance from $30.2^{\circ} \mathrm{C}$ to $27.1^{\circ} \mathrm{C}$ in the shallow-water shrimp Palaemon varians acclimated to $10^{\circ} \mathrm{C}$. Statistically significant shifts in phospholipid fatty acid composition occurred during exposure to high hydrostatic pressure, suggesting that homeoviscous modifications support shifts in environmental tolerances during hyperbaric acclimation. Despite the reduction in temperature tolerance, $P$. varians retains sufficient thermal scope to tolerate the thermal regime in the hydrothermal vent environment, allowing for the possibility of direct deep-sea hydrothermal vent colonisation by shallow-water shrimp.
\end{abstract}

\section{Introduction}

Extant deep-sea faunas are descended from shallow-water ancestors (see Brown and Thatje, 2014). Understanding the physiological adaptations that allowed shallow-water organisms to repeatedly colonise diverse deep-sea environments and establish the present high biodiversity is of fundamental interest to deep-sea biologists and ecologists. Deep-sea hydrothermal vents are of particular interest due to putatively extreme environment conditions present (high hydrostatic pressure, high temperature variability, high concentrations of potentially toxic chemical species). Alvinocarid hydrothermal vent shrimp represent key elements of hydrothermal vent communities in the Mid-Atlantic Ridge, and in the Pacific and Indian Oceans (Lunina and Vereshchaka, 2014). These shrimp appear to have originated in the Late Eocene/Early Oligocene $(\sim 35 \mathrm{Ma})$, arising from non-hydrothermal vent deep-sea shrimp, which themselves arose from shallow-water shrimp (Sun et al., 2018b). This shallow-water ancestry suggests that alvinocarid shrimp and shallow-water shrimp are appropriate for comparative studies, through which valuable understanding can be gained of physiological adaptations to deep-sea hydrothermal vent conditions.

Alvinocarid shrimp demonstrate varying degrees of adaptation to hydrothermal conditions with adaptations ranging from few and inconspicuous, to numerous and prominent (Lunina and Vereshchaka, 2014). For example, Alvinocaris spp. appear similar to non-vent deepsea shrimp. In contrast, Mirocaris spp. and Rimicaris spp. display conspicuous morphological and ecological adaptations (Lunina and Vereshchaka, 2014), such as the dorsal thoracic modified compound eye in Rimicaris spp. which putatively detects light emitted by hydrothermal vents (O'Neill et al., 1995). Hydrothermal vent taxa are typically considered models of extreme temperature adaptation. For example, the thermal optimum of the Pompeii worm Alvinella pompejana exceeds $42^{\circ} \mathrm{C}$ (Ravaux et al., 2013). However, hydrothermal vent shrimp do not appear to demonstrate higher maximum critical temperatures than shallow-water shrimp (Shillito et al., 2006; Mestre et al., 2015) despite occupying what is putatively the most extreme thermal marine environment. For example, the critical thermal maximum reported for $M$. fortunata matches the modelled critical thermal maximum of shallow-water shrimp acclimated to $19^{\circ} \mathrm{C}$ (Mestre et al., 2015),

\footnotetext{
* Corresponding author.

E-mail address: alastair.brown@noc.soton.ac.uk (A. Brown).
} 
M. fortunata's preferred temperature (Smith et al., 2013). Yet comparisons between critical thermal tolerance of deep-sea and shallow-water shrimp must be treated with caution. Assessments of both hydrothermal-vent and shallow-water shrimp species temperature tolerances have been made at native hydrostatic pressures only. Thus, the potential influence of hydrostatic pressure adaptation on temperature tolerance remains unexplored.

The physiological effects of high hydrostatic pressure present a significant impediment to colonisation of the deep sea by shallow-water crustaceans (Brown and Thatje, 2014, 2015). Deep-sea hydrothermalvent shrimp appear adapted to high hydrostatic pressure. The bathymetric distribution of hydrothermal-vent shrimp extends beyond the hydrostatic pressure tolerance of shallow-water shrimp at in situ temperatures (Oliphant et al., 2011; New et al., 2014) and some hydrothermal-vent shrimp species are thought to be excluded from shallow vent fields by relatively low hydrostatic pressure (Yahagi et al., 2015). Even deep-sea hydrothermal-vent shrimp that survive at surface pressures may be adversely affected by these conditions. For example, metabolic rate in $M$. fortunata is depressed following depressurisation of shrimp sampled at $1617 \mathrm{~m}$ depth (Shillito et al., 2006). Pressure-related shifts in $M$. fortunata's metabolic rate are not transient or overcome by acclimation to surface pressure: metabolic rate in $M$. fortunata declines further with sustained exposure to surface pressure [cf. Shillito et al., 2006, Smith et al., 2013). The effects of sustained low pressure exposure may even contribute to apparent metabolic adaptations to the acute spatial and temporal scale of temperature changes inherent in the vent environment such as reduced metabolic sensitivity to temperature reported in $\boldsymbol{M}$. fortunata (Smith et al., 2013).

In contrast, acclimation to high hydrostatic pressure increases acute hydrostatic pressure tolerance in the shallow-water shrimp Palaemon varians (New et al., 2014). New et al. (2014) suggest that this may be due to homeoviscous modifications in cell membrane lipid bilayers. Adjustment to cell membrane phospholipid fatty acid composition (homeoviscous acclimation) is crucial to maintaining the function of cell membranes: phospholipid fatty acid composition modulates membrane fluidity, determining membrane permeability and affecting mobility and function of cell membrane proteins (Guschina and Harwood, 2006). Both hydrostatic pressure and temperature affect the fluidity of cell membranes and thus membrane functioning (Hazel and Williams, 1990; Hazel, 1995). Typical responses to increased pressure or decreased temperature include increasing the proportion of unsaturated fatty acids in cell membranes, which maintains membrane fluidity (Guschina and Harwood, 2006; Hazel and Williams, 1990; Hazel, 1995). Such modifications do not occur in the very short term during cold acclimation (e.g. 24 h; Rongers et al., 2012), but can occur over slightly longer time scales (e.g. $72 \mathrm{~h}$; Waagner et al., 2013). Unsaturation of phospholipid-derived fatty acids in response to high hydrostatic pressure may result in reduced acute thermal tolerance, but whether this is the case, and whether shifts in environmental tolerances during hydrostatic pressure acclimation are dependent on homeoviscous acclimation has yet to be studied. Identifying the effects of acclimation to high hydrostatic pressure on acute temperature tolerance and phospholipid fatty acid composition in a shallow-water shrimp may resolve this uncertainty, whilst also offering insight into the possibility of direct colonisation of deep-sea hydrothermal vents by shallow-water shrimp.

The shallow-water species Palaemon varians has been used as a comparator for deep-living shrimps (Gonzalez-Rey et al., 2006, 2007; Smith et al., 2013; Brown et al., 2017a). P. varians (recently identified as the senior synonym of Palaemonetes varians; De Grave and Ashelby, 2013), a temperate brackish-water shrimp, has emerged as a model species for hyperbaric and thermal stress physiology and ecotoxicology through experiments assessing behavioural, respiratory, and molecular responses to acute and sustained temperature, hydrostatic pressure, and toxic metal exposures (Cottin et al., 2010; Oliphant et al., 2011; Cottin et al., 2012; Ravaux et al., 2012; Smith et al., 2013; New et al., 2014; Morris et al., 2015a,b,c; Brown et al., 2017a; Brown and Hauton, 2018).
Experimentation has revealed that temperature regimes tolerated by $P$. varians are comparable to those of hydrothermal vent shrimp, and the acute temperature tolerance of palaemonid (including P. varians) and hydrothermal vent shrimp are similar at their native hydrostatic pressures (Ravaux et al., 2003; Shillito et al., 2006; Oliphant et al., 2011; Ravaux et al., 2012; Mestre et al., 2015). Further, P. varians' sustained hyperbaric tolerance extends to the depth of some hydrothermal vents inhabited by vent shrimp (New et al., 2014; Cottin et al., 2012; Morris et al., 2015a). P. varians therefore appears a suitable comparator for hydrothermal vent shrimp. Here, we report on the effects of high hydrostatic pressure acclimation on critical thermal tolerance and cell membrane lipid bilayer composition in the shallow-water palaemonid shrimp Palaemon varians.

\section{Materials and methods}

\subsection{Capture and maintenance of Palaemon varians}

Approximately 130 adult Palaemon varians were collected from Lymington salt marshes (Hampshire, UK) on the 4th of February 2014. Sampling was carried out using a hand net towed near ditch margins. Shrimp were transferred to the National Oceanographic Centre Southampton (NOCS) in 101 buckets containing water from the collection site. At the NOCS, shrimp were transferred to 101 aquaria containing $8.5^{\circ} \mathrm{C}$ and 25 salinity seawater aerated via bubble stones attached to air pumps. Aquaria were then placed in temperature-controlled conditions at $10.0^{\circ} \mathrm{C}$ with $12: 12$ photoperiod. Shrimp were fed with Tetra Goldfish flakes to excess three times per week. Water changes were conducted three times per week on alternate days to feeding ( $50 \%$ water change; $10.0^{\circ} \mathrm{C}, 32.4$ salinity, $1 \mu \mathrm{m}$-, UV-filtered seawater). Animals were maintained in captivity for at least 4 weeks before experimental exposures.

\subsection{Effect of pressure acclimation on critical thermal maximum $\left(C T_{\max }\right)$}

Both thermal and hyperbaric tolerance typically decrease during ontogeny (Mestre et al., 2013), including in crustaceans (e.g., Munro et al., 2015; Brown et al., 2017b). Consequently, experimental approaches focused on adults. To reduce potential variability in response resulting from differences in digestive state, shrimp were starved for 3 days before experimentation.

To determine critical thermal maximum $\left(\mathrm{CT}_{\max }\right)$ three replicate treatments were performed. In each replicate treatment ten shrimp were transferred from aquaria in the temperature-controlled room into a PVC cage with an inclined lid within the high pressure flow-through IPOCAMP system run at experimental temperature for at least $1.5 \mathrm{~h}$ (Ravaux et al., 2003; Shillito et al., 2001, 2006). Shrimp were then maintained in the IPOCAMP for $1 \mathrm{~h}$ before initiating treatments to allow shrimp to recover from handling stress.

Temperature and pressure within the IPOCAMP system were recorded throughout treatments using a temperature/pressure data logger (SP2T4000, NKE instrumentation). For control treatments, the shrimp were maintained within the IPOCAMP system at atmospheric pressure $(0.1 \mathrm{MPa})$ for 7 days $(168 \mathrm{~h})$ before assessment of $\mathrm{CT}_{\max }$. For experimental treatments, pressure was increased from $0.1 \mathrm{MPa}$ to $10 \mathrm{MPa}$ stepwise by $1 \mathrm{MPa} 5 \mathrm{~min}^{-1}$ and then maintained for 7 days (168 h) before assessment of $\mathrm{CT}_{\max }$. On days 3 and 5 of the treatment a 101 water change $\left(10.0^{\circ} \mathrm{C}, 32.4\right.$ salinity, $1 \mu \mathrm{m}$-, UV-filtered seawater) of the unpressurised 401 reservoir tank was performed, without affecting hydrostatic pressure within the pressurised component of the system. No mortalities were observed during the 168-h acclimation period in control or experimental treatments. In both control and experimental treatments, temperature within the IPOCAMP system was increased at a constant rate by $0.26^{\circ} \mathrm{C} \mathrm{min}^{-1}$ following the 168 -h acclimation period.

A video camera attached to an endoscope and connected to a digital video recorder was used to record shrimp behaviour. The endoscope 
was inserted into the central viewing port in the IPOCAMP lid. Illumination was provided by cold lights inserted into other viewing ports in the IPOCAMP lid. Video recording began $15 \mathrm{~min}$ before the start of the temperature increase. The behaviour of each individual shrimp was assessed though video-analysis for the $15 \mathrm{~s}$ before and after the temperature within the system reached each $1{ }^{\circ} \mathrm{C}$ increment. The behaviour of each individual shrimp was categorised (following Ravaux et al., 2003; Shillito et al., 2006; Oliphant et al., 2011; New et al., 2014; Morris et al., 2015c; Pallareti et al., 2018) as:

1. Movement - detectable movement of any kind except Active Movement (see below): pereopod or pleopod movements; scaphognathite beating; antennal lateral sweeping; cleaning of mouth parts by rubbing them along each other.

2. Active Movement (AM) - walking or swimming a distance greater than own body length in less than 30s.

3. Motionless - no detectable movement at normal tape-reading speed.

4. Loss of Equilibrium (LoE) - resting on the bottom in either a 'sideways' or 'upside-down' position for $>2 \mathrm{~s}$.

LoE could co-occur with any other behaviour, but Movement, Active Movement, and Motionless were mutually exclusive. LoE was interpreted as an indicator behaviour of loss of function and AM was interpreted as an indicator behaviour of stress (following Ravaux et al., 2003; Shillito et al., 2006; Oliphant et al., 2011; Morris et al., 2015c; Pallareti et al., 2018).

\subsubsection{Statistical analysis}

A logistic regression was used to model the LoE response to increasing temperature and predict $\mathrm{CT}_{\max }$, assuming a logistic distribution based on the sigmoidal data pattern (Fig. 1). Statistical analysis was performed using R and RStudio software (v. 3.0.2 and v. 0.98.501; $\mathrm{R}$ Core Team, 2013). $\mathrm{CT}_{\max }$ was assessed as the temperature at which $50 \%$ of shrimp experienced LoE.

The effect of pressure acclimation on Active Movement was

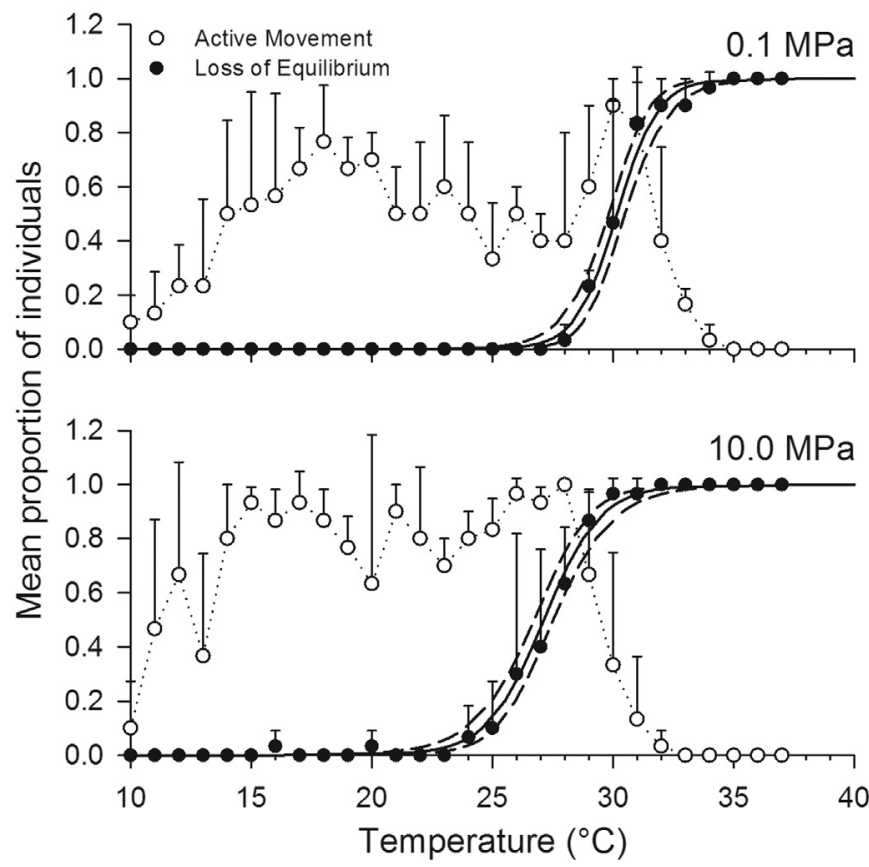

Fig. 1. Temperature tolerance of Palaemon varians after acclimation to different pressures (0.1 MPa and 10.0 MPa) for 1 week at $10^{\circ} \mathrm{C}$. Open and closed circles respectively represent Active Movement and Loss of Equilibrium (mean + SD for clarity; $n=3$ ) at different temperatures during a thermal ramp. The solid line and dashed lines represent LoE and 95\% confidence intervals modelled using probit analysis, assuming a logistic distribution. analysed using a General Linear Model (GLM) Analysis of Variance (ANOVA) comparing AM at each temperature. Data were proportional and therefore were arcsine square root transformed prior to statistical analysis to achieve homogeneity of variance. The post-hoc multiple pairwise comparisons Šidak Simultaneous test was used to determine which treatments were significantly different in both GLM ANOVA analyses.

\subsection{Phospholipid fatty acid composition}

The effect of hyperbaric acclimation on phospholipid fatty acid composition in $P$. varians was assessed in separate treatments. 10 adult shrimp were exposed to each of the 168-h control and experimental acclimations described above. No mortalities were observed during the acclimation period in control or experimental treatments. Subsequent to the acclimation period shrimp were not exposed to the thermal ramp used to determine $\mathrm{CT}_{\max }$, but were removed from the IPOCAMP instead (Cottin et al., 2012). Depressurisation in the experimental treatment was acute (few seconds). Shrimp were rapidly decapitated: single clean cuts were made vertically from the dorsal extension of the carapace, separating the carapace and the first abdominal segment. The abdomen sections were placed individually in $1.5 \mathrm{ml}$ centrifuge tubes, frozen in liquid nitrogen, and stored at $-80^{\circ} \mathrm{C}$ for subsequent analysis. Abdomen sections were selected for subsequent analysis because previous study identified greater responses to high hydrostatic pressure in the abdomen of P. varians than in its head (Morris et al., 2015c). Both temperature and pressure within the IPOCAMP system were recorded throughout the treatments using a temperature/pressure data logger (SP2T4000, NKE instrumentation).

$1.5 \mathrm{ml}$ centrifuge tubes containing individual abdomen sections ( $n=3$ per treatment selected at random) were removed from $-80^{\circ} \mathrm{C}$ storage and individual tissue samples were homogenised (using an IKA T10 Basic Ultra-Turrax homogenizer) in chloroform:methanol (2:1, $v /$ v). Total lipid was extracted according to (Folch et al., 1957). Samples were thoroughly vortexed following the addition of aqueous potassium chloride $(0.88 \%, w / v)$, then centrifuged for $5 \mathrm{~min}$ at $1500 \mathrm{rpm}$ to establish a biphasic system. The upper phase (non-lipid substances in aqueous methanol) was removed via pipetting and discarded. The lower phase (lipid in chloroform) was filtered through a Whatman No.1 filter paper, pre-washed with chloroform:methanol 2:1 v/v, into pre-weighed vials. Samples were then dried down under $\mathrm{N}_{2}$ gas using an N-EVAP system (Organomation), placed in a desiccator for $1 \mathrm{~h}$, weighed to establish total lipid mass, and redissolved in chloroform to a final concentration of $1 \mathrm{mg} \mathrm{ml}^{-1}$. Samples were stored at $-20{ }^{\circ} \mathrm{C}$.

Phospholipids were purified by thin layer chromatography (TLC). A $1 \mathrm{mg}$ aliquot of total lipid was run on $2 \mathrm{~mm}, 20 \times 20 \mathrm{~cm}$ silica gel plates in a hexane:diethyl ether:acetic acid (80:20:2 v/v/v) solvent system. To enable lipid visualisation under ultraviolet light, plates were sprayed with $2^{\prime}, 7$ 'dichloro-fluorescein in methanol $(0.1 \%, \mathrm{w} / \mathrm{v})$. Phospholipids were scraped off plates into vials in which trans-methylation reactions were established following Christie (1982). Scrapings were dissolved in $1 \%$ sulphuric acid in methanol and toluene $(1: 2 \mathrm{v} / \mathrm{v})$ and incubated at $50{ }^{\circ} \mathrm{C}$ for $16 \mathrm{~h}$. Subsequently, equal volumes of hexane:diethyl ether $(1: 1 \mathrm{v} / \mathrm{v})$ and deionised milli-Q water were added and samples were mixed thoroughly by vortexing. A biphasic system was established though centrifuging for $2 \mathrm{~min}$ at $1500 \mathrm{rpm}$. The upper phase was removed into a vial and aqueous sodium bicarbonate $(2 \% \mathrm{w} / \mathrm{v})$ was added. Samples were mixed thoroughly by vortexing. A biphasic system was established through centrifuging for $2 \mathrm{~min}$ at $1500 \mathrm{rpm}$. The upper solvent fraction was removed into vials and dried down under $\mathrm{N}_{2}$ gas. This purified phospholipid fraction was redissolved in $\sim 0.1 \mathrm{ml}$ hexane. The solution was run through a TRACE2000, Thermo Electron, Gas Chromatograph (Thermo Scientific, UK) equipped with a Restek Stabilwax column $(0.32 \mathrm{~mm}$ i.d. $\times 30 \mathrm{~m})$. Hydrogen was used as the carrier gas (Pond et al., 2014). 
Table 1

Critical temperature maximum $\left(\mathrm{CT}_{\max }\right.$ ) loss of equilibrium (LoE) model parameters, with values for critical thresholds.

\begin{tabular}{lllll}
\hline Acclimation & $\mathrm{a}$ & $\mathrm{b}$ & Goodness of fit (Deviance $P$ ) & $\mathrm{CT}_{\max }\left({ }^{\circ} \mathrm{C}\right)$ \\
\hline $10^{\circ} \mathrm{C}, 0.1 \mathrm{MPa}$ & -35.7609 & 1.1854 & 0.999 & 30.2 \\
$10^{\circ} \mathrm{C}, 10.0 \mathrm{MPa}$ & -23.2365 & 0.8564 & 0.737 & 27.1
\end{tabular}

Models were derived using probit analysis of LoE data, assuming a logistic distribution: $\ln \left[\frac{Y}{1-Y}\right]=a+b X$, where $X$ is the exposure temperature or pressure and $Y$ is the proportion of individuals demonstrating LoE (following New et al., 2014).

\subsubsection{Statistical analysis}

Phospholipid fatty acid data were expressed as percent composition of total fatty acids. Thus phospholipid fatty acid data were proportional and were therefore arcsine-square-root transformed prior to statistical analysis. Statistically significant differences within each exposure duration treatment were assessed by one-way ANOVA, with hydrostatic pressure as the fixed factor $(\alpha=0.05)$.

\section{Results}

\subsection{Effect of pressure acclimation on critical thermal maximum $\left(C T_{\max }\right)$}

Loss of Equilibrium models did not differ significantly from observed LoE data (Goodness-of-fit Deviance $p>$.05). LoE was significantly affected by acclimation to $10 \mathrm{MPa}(p<.001)$ (Fig. 1, Table 1$)$. Temperature tolerance $\left(\mathrm{CT}_{\max }\right)$ was significantly lower at $10 \mathrm{MPa}\left(27.1^{\circ} \mathrm{C}\right)$ than at $0.1 \mathrm{MPa}\left(30.2^{\circ} \mathrm{C}\right)$. Further, the gradient of the modelled LoE response was significantly lower at $10 \mathrm{MPa}$ than at $0.1 \mathrm{MPa}$, indicating a less acute temperature effect $(p=.026)$ (Fig. 1 , Table 1).

The effect of temperature on Active Movement was affected by acclimation pressure $\left(F_{27,112}=3.024, p<.001\right)$ (Fig. 1$)$. Temperatures resulting in significant differences were determined using the post-hoc multiple pairwise comparisons Holm-Sidak test. AM initially increased with increasing temperature at both acclimation pressures, but significant increase in $\mathrm{AM}$ occurred at lower temperature at $10.0 \mathrm{MPa}$ $\left(15^{\circ} \mathrm{C}\right)$ than at $0.1 \mathrm{MPa}\left(17^{\circ} \mathrm{C}\right)$. AM decreased steeply at the onset of LoE.

\subsection{Phospholipid fatty acid composition}

Phospholipid fatty acid composition was significantly affected by acclimation to high hydrostatic pressure (Fig. 2).

\section{Discussion}

4.1. Hyperbaric acclimation effects on critical thermal maximum ( $\left.C T_{\max }\right)$ and phospholipid fatty acid composition

The $\mathrm{CT}_{\max }$ of shrimp is known to depend on acclimation temperature (Ravaux et al., 2016). The $\mathrm{CT}_{\max }$ of $P$. varians acclimated to surface hydrostatic pressure $(0.1 \mathrm{MPa})$ at $10^{\circ} \mathrm{C}$ in this study was similar to that of a previous study: respectively, $30.2^{\circ} \mathrm{C}$ and $30.9^{\circ} \mathrm{C}$ (Oliphant et al., 2011). Although $\mathrm{CT}_{\max }$ differs by $0.7^{\circ} \mathrm{C}$ between studies, this difference is likely due to differing acclimation periods. $\mathrm{CT}_{\max }$ decreases rapidly during the first days of acclimation to low temperature, but thermal acclimation continues for $20+$ days and $\mathrm{CT}_{\max }$ decreases further during this period (New et al., 2014). Whereas shrimp in this study were acclimated to $10^{\circ} \mathrm{C}$ for at least 5 weeks prior to assessment of thermal tolerance, shrimp in Oliphant et al.'s (2011) study were acclimated shrimp to $10{ }^{\circ} \mathrm{C}$ for only 3 days prior to assessment of thermal tolerance.

Acclimation for 7 days to high hydrostatic pressure $(10 \mathrm{MPa})$ at $10{ }^{\circ} \mathrm{C}$ reduced the acute temperature tolerance of adult shallow-water shrimp Palaemon varians by $3.1{ }^{\circ} \mathrm{C}$, from $30.2^{\circ} \mathrm{C}$ to $27.1^{\circ} \mathrm{C}$. Identical acclimation treatment increased acute hydrostatic pressure tolerance in P. varians by $2.1 \mathrm{MPa}$ (New et al., 2014), suggesting that the decrease in acute temperature tolerance is not an artefact of increased stress at high hydrostatic pressure. Both $\mathrm{CT}_{\max }$ observed for P. varians acclimated to $10^{\circ} \mathrm{C}$ at 0.1 and at $10 \mathrm{MPa}$ are lower than that observed for $M$. fortunata at its native pressure $\left(36 \pm 1{ }^{\circ} \mathrm{C}\right.$; Shillito et al., 2006), demonstrating that the hydrothermal vent shrimp is physiologically adaptated to the high hydrostatic pressure and thermally variable conditions of hydrothermal vent environments.

Homeoviscous adaptations to cell membrane bilayer have been demonstrated for organisms adapted to extreme cold and high pressure and have been posited as a mechanism of acclimation to low temperature and high hydrostatic pressure (Hazel and Williams, 1990). Adaptations comprise shifts in the composition of cell lipid bilayers towards increased proportions of mono- and poly-unsaturated fatty acids and decreased saturated fatty acids under conditions of low temperature and high hydrostatic pressure, maintaining membrane fluidity and therefore function under these conditions. The changes in acute temperature tolerance and acute hyperbaric tolerance demonstrated for $P$. varians after acclimation to $10 \mathrm{MPa}$ occur alongside small but significant shifts in phospholipid fatty acid composition. Although there was no significant change in total monounsaturated, total polyunsaturated, or total unsaturated phospholipid fatty acids, there were significant changes in some individual phospholipid fatty acids. Some shifts in individual phospholipid fatty acids were consistent with the prediction based on the homeoviscous acclimation hypothesis that the proportion of unsaturated fatty acids in cell membranes increases in response to high hydrostatic pressure: 16:1n-7 (palmitoleic acid), 20:4n-6 (arachidonic acid), 22:5n-3 (docosapentaenoic acid), 16:2 (hexadecadienoic acid), and 16:4n-1 (hexadecatetraenoic acid) all increased significantly. Increases in unsaturated fatty acids may result in increased membrane fluidity (Hazel and Williams, 1990; Hazel, 1995). For example, significant increase in palmitoleic acid has been reported to contribute to maintaining membrane fluidity in amphipods in response to decreased temperature (e.g. Lahdes et al., 2000). Whilst maintaining membrane fluidity contributes to maintaining essential membrane function at low temperature or high pressure, increased membrane unsaturation also results in greater leakage across membranes (Hazel and Williams, 1990; Hazel, 1995). Proton leakage across the inner mitochondrial membrane is proposed to contribute to limiting critical thermal tolerance by increasing oxygen demand beyond oxygen supply capacity as temperature increases (Pörtner, 2001). Thus increased proton leakage across the inner mitochondrial membrane resulting from unsaturation of the membrane may contribute to the observed reduction in critical thermal tolerance observed with acclimation to high hydrostatic pressure. Indeed, positive selection analysis indicates adaptive change in the mitogenome of the alvinocarid shrimp Shinkaicaris leurokolos related to the electron transport chain (Sun et al., 2018a) which is coupled with proton transfer and may thus affect critical temperature tolerance.

The reason that only few unsaturated phospholipid fatty acids were observed to increase significantly may also be related to their specific functions. For example, docosapentaenoic acid is thought to have a role in attenuating decrease in long-term potentiation in synapse (Kaur et al., 2011). Thus increase in docosapentaenoic acid may counteract adverse effects of high hydrostatic pressure on the function of crustacean neuromuscular synapse (Sébert, 2010; Brown et al., 2017b), which have been reported to demonstrate long-term potentiation (Baxter et al., 1985). In contrast, specific functions of hexadecadienoic and hexadecatetraenoic acids are uncertain. Despite this, the increase in hexadecatetraenoic acid in P. varians in response to high hydrostatic pressure may be particularly interesting. Hexadecatetraenoic acid is an unusual fatty acid which has only been reported in marine phytoplankton, amoeba, and the krill Euphausia superba, and it has been unclear whether hexadecatetraenioc acid is synthesised in E. pacifica or 

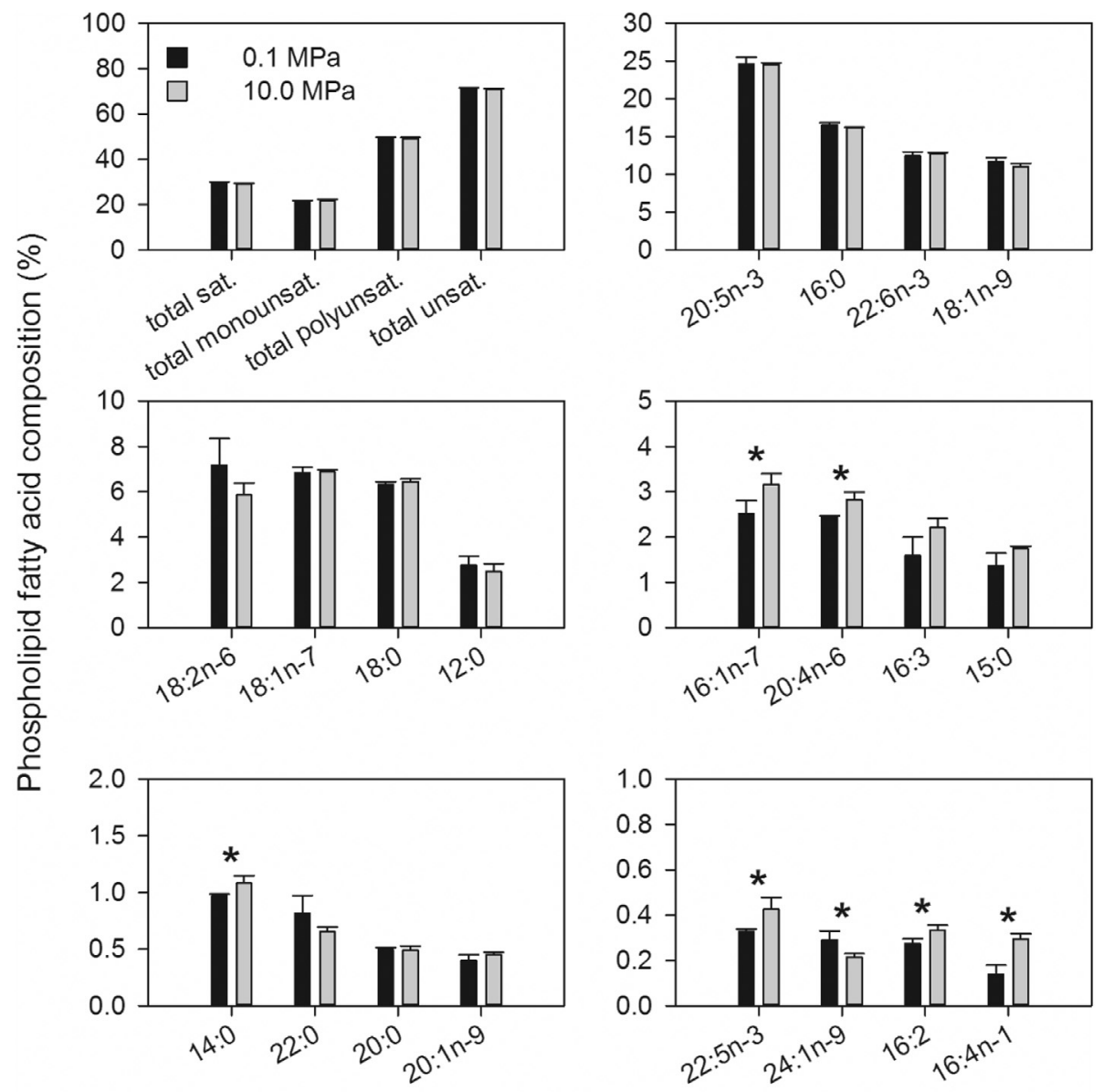

\section{Phospholipid fatty acid}

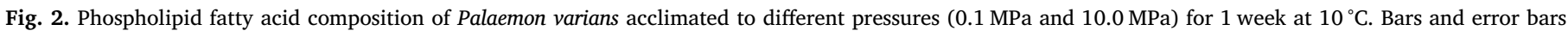

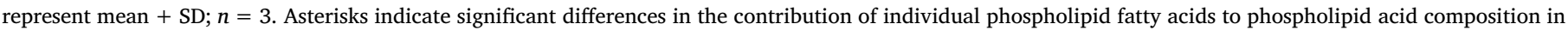
shrimp acclimated to different pressures.

derived from phytoplankton (Yamada et al., 2017). Results presented here suggest that starved P. varians is capable of synthesising hexadecatetraenoic acid in response to increased hydrostatic pressure, raising the possibility that the presence of hexadecatetraenoic acid in E. pacifica may relate to diurnal vertical migration of up to $400 \mathrm{~m}$ in this species (Endo and Yamano, 2006).

The observed shifts in fatty acid composition in $P$. varians also suggest that responses to high hydrostatic pressure are more complex than simply increasing the proportion of unsaturated fatty acids in cell membranes. For example, the significant increase in the saturated fatty acid 14:0 (myristic acid) may be unexpected. However, myristic acid has a specific role in acylation of membrane proteins and anchoring those proteins to the cell membrane (Calder, 2015). Thus, the increase in myristic acid may reflect increased protein concentration in the cell membrane in response to the impaired function of membrane proteins such as $\mathrm{Na}^{+} \mathrm{K}^{+}$ATPase (Gibbs and Somero, 1989) at high hydrostatic pressure. $\mathrm{Na}^{+} \mathrm{K}^{+}$ATPase is important in maintaining $\mathrm{Ca}^{2+}$ homeostasis in crustaceans (Freire et al., 2008) and is crucial to maintaining membrane potential required to generate action potential in cells regulating cardiac function (Lodish et al., 2003).

Similarly, although not statistically significant, the apparent reduction in polyunsaturated 18:2n-6 (linoleic acid) is unexpected. Linoleic acid is an essential fatty acid that cannot be synthesised from other dietary components and therefore the proportion of linoleic acid in cell membranes will decrease if linoleic acid is metabolised. Linoleic acid is a precursor to arachidonic acid (20:4n-6) (Calder, 2015), which increased significantly in response to high hydrostatic pressure.
Arachidonic acid levels play a role in determining eicanosoid production: arachidonic acid is the precursor to a range of eicanosoids such as prostaglandins, thromboxanes, and leukotrienes that have many regulatory roles in cell growth and in the central nervous system (Needleman et al., 1988, Calder, 2015). Both cell growth and central nervous system function are known to be adversely affected by high hydrostatic pressure (Sébert, 2010; Brown et al., 2017b). Arachidonic acid also has a role in cell signalling: arachidonic acid is also known to interact with voltage- and ligand-gated ion channel functions (Antollini and Barrantes, 2016). For example, arachidonic acid synthesis is linked to NMDA receptor activity (Dumuis et al., 1988). NMDA receptor activity is reported to increase in crustaceans including $P$. varians in response to high hydrostatic pressure (Morris et al., 2015a,b,c; Munro et al., 2015; Brown et al., 2017b; Brown and Thatje, 2018). The significant decrease in 24:1n-9 (nervonic acid) may also be related to the effects of high hydrostatic pressure on central nervous system function. Nervonic acid is incorporated in the myelin sheath of nerve fibres during nerve biosynthesis (Stoffel and Bosio, 1997), which may be a response to the adverse effects of high hydrostatic pressure.

Although observed changes in phospholipid fatty acids suggest that homeoviscous acclimation may contribute to adjustments in critical thresholds, further experimentation with greater replication is required to confirm this, and other acclimation mechanisms may also contribute to shifts in environmental tolerances. For example, cytoprotective molecules such as the osmolyte trimethylamine N-oxide (TMAO) counteract the inhibitory effects of pressure on the stability and function of many proteins (Yancey and Siebenaller, 2015) and may be involved in 
acclimation to high hydrostatic pressure in crustaceans: TMAO is reported to increase with depth in amphipods (Downing et al., 2018). Similarities in the effects of low temperature and high hydrostatic pressure have prompted the suggestion that increases in mitochondrial densities and changes in mitochondrial functional properties that are observed during cold acclimation (Pörtner, 2002) may also occur during acclimation to high hydrostatic pressure (New et al., 2014). No data are yet available to assess these possibilities.

Remodelling membrane composition at high hydrostatic pressure may be more important in hyperbaric acclimation than suggested by phospholipid fatty acid data presented here. Membrane phospholipid fatty acid remodelling may occur over longer timescales or may depend on dietary assimilation of phospholipids. Studies that have assessed the effect of acclimation to high hydrostatic pressure have not explored the impact of feeding on acute environmental tolerances (e.g., New et al., 2014; Brown et al., 2017b) due to the technological difficulties in introducing food into hyperbaric aquaria. Similarly, P. varians were not fed during the 7 day treatments within the hyperbaric aquaria. Hypothetically, assimilation of appropriate dietary phospholipids and subsequent bilayer remodelling could increase tolerance of high hydrostatic pressure in shallow-water organisms. Studies on the effects of feeding during hyperbaric exposures are necessary to understand better acclimation to high hydrostatic pressure.

\subsection{Ecological implications of hyperbaric acclimation effects on $C T_{\max }$}

Critical thermal tolerance in $P$. varians following 7-day acclimation to $5{ }^{\circ} \mathrm{C}$ at $0.1 \mathrm{MPa}$ is $27.3{ }^{\circ} \mathrm{C}$ (New et al., 2014), similar to the $27.1{ }^{\circ} \mathrm{C}$ observed here following 7 -day acclimation to $10.0 \mathrm{MPa}$ at $10^{\circ} \mathrm{C}$. The effects of low temperature and high hydrostatic pressure acclimation are typically cumulative or synergistic, suggesting that acclimatisation to the environmental conditions in the non-hydrothermal vent deep sea environment (low temperature $5{ }^{\circ} \mathrm{C}$ and high hydrostatic pressure $10.0 \mathrm{MPa}$ ) would result in $\mathrm{CT}_{\max }$ reduction below $\sim 24^{\circ} \mathrm{C}$. Nonetheless, $\mathrm{CT}_{\text {max }}$ would remain sufficient in P. varians to allow occupation of known hydrothermal vent habitats.

Although P. varians inhabits a similar thermal range to hydrothermal vent shrimp the spatial/temporal scale in temperature variation differs significantly. Temperatures experienced by $P$. varians in salt marsh habitat range from $0{ }^{\circ} \mathrm{C}$ in winter to $33^{\circ} \mathrm{C}$ in summer, but with no $>6{ }^{\circ} \mathrm{C}$ variation in a $12 \mathrm{~h}$ period (Pallareti et al., 2018). In contrast, hydrothermal vent shrimp such as $M$. fortunata occur in high abundances within $1 \mathrm{~m}$ of hot fluid outflows in hydrothermal vent fields (Marcon et al., 2013), with thermal distribution ranging from 4 to $24.6{ }^{\circ} \mathrm{C}$ (Desbruyeres et al., 2001). Although $M$. fortunata preferentially selects a mean temperature $<1{ }^{\circ} \mathrm{C}$ greater than $P$. varians (respectively $19.2^{\circ} \mathrm{C}$ and $18.3^{\circ} \mathrm{C}$ at $0.1 \mathrm{MPa}$; Smith et al., 2013), M. fortunata appears to have evolved reduced metabolic sensitivity in response to the acute spatial and temporal scale of temperature changes in the hydrothermal vent environment (Smith et al., 2013). Nonetheless, it is likely that $P$. varians acclimated to high hydrostatic pressure and low temperature retain capacity to tolerate the thermal regime in the hydrothermal vent environment. Given that related extant shallow-water and hydrothermal-vent shrimp are physiologically capable of coping with the thermal and hyperbaric conditions of the hydrothermal vent environment, the common ancestor of these lineages may have possessed similar capability, allowing for the possibility of direct hydrothermal vent colonisation by shallow-water shrimp.

In contrast, the chemical composition of the hydrothermal environment is likely to have represented a barrier to direct vent colonisation by shallow-water shrimp. Recent ecotoxicological assessments suggest that the hydrothermal vent environment would prove toxic to P. varians (Brown et al., 2017a). Whilst the hydrothermal vent shrimp appear to have evolved physiological strategies to mitigate metal-rich vent seawater (Auguste et al., 2016), the common ancestor of hydrothermal vent and shallow-water shrimp is likely to have lacked adaptations to tolerate deep-sea hydrothermal vent seawater chemistry. Direct colonisation of the deep-sea hydrothermal vent environment may therefore be unlikely. Indeed, Alvinocarididae hydrothermal vent shrimp share closer affinities with other deep-water shrimp families and non-hydrothermal vent shrimp families with both shallow-water and deep-water representatives, than with exclusively shallow-water shrimp families (Bracken et al., 2009; Li et al., 2011; Aznar-Cormano et al., 2015; Hernández-Ávila et al., 2015; Liao et al., 2017; Davis et al., 2018; Sun et al., 2018b). This suggests that shrimp colonised the wider deepsea environment before colonising hydrothermal vents.

\subsection{Conclusion}

Acclimation to high hydrostatic pressure reduces temperature tolerance in the shallow-water palaemonid shrimp Palaemon varians. Such physiological plasticity may have been an important factor in the colonisation of deep-sea environments by shallow-water shrimp, but $P$. varians acclimated to high hydrostatic pressure and low temperature likely retain sufficient thermal scope to tolerate the hydrothermal vent environment. Nonetheless, it appears shrimp colonised the wider deep sea before colonising deep-sea hydrothermal vents. Shifts in phospholipid fatty acid composition during hyperbaric exposure suggest that homeoviscous modifications in the cell lipid bilayer contribute to observed shifts in critical temperature and critical pressure tolerances during hyperbaric acclimation.

\section{Acknowledgements}

$\mathrm{AB}, \mathrm{AO}$, and ST conceived and designed experiments. $\mathrm{AB}, \mathrm{AM}$, and $A O$ performed experimental treatments. $A O$ and $D P$ performed lipid biochemical analysis. $\mathrm{AB}, \mathrm{AM}$, and $\mathrm{AO}$ analysed data. $\mathrm{AB}$ and $\mathrm{AO}$ wrote the manuscript, with all authors contributing critically. AB was supported through a Natural Environment Research Council PhD studentship. AO was supported through a MASTS bursary to DP and ST. The authors are grateful for the constructive review process that significantly improved the manuscript.

\section{Ethical approval}

All applicable international, national, and/or institutional guidelines for the care and use of animals were followed.

\section{References}

Antollini, S.S., Barrantes, F.J., 2016. Fatty acid regulation of voltage- and ligand-gated ion channel function. Front. Physiol. 7, 573.

Auguste, M., Mestre, N.C., Rocha, T.L., Cardoso, C., Cueff-Gauchard, V., Le Bloa, S., Cambon-Bonavita, M.A., Shillito, B., Zbinden, M., Ravaux, J., Bebianno, M.J., 2016. Development of an ecotoxicological protocol for the deep-sea fauna using the hydrothermal vent shrimp Rimicaris exoculata. Aquat. Toxicol. 175, 277-285.

Aznar-Cormano, L., Briset, J., Chan, T.-Y., Corbari, L., Puillandre, N., Utge, J., Zbinden, M., Zuccon, D., Samedi, S., 2015. An improved taxonomic sampling is a necessary but not sufficient condition for resolving inter-families relationships in Caridean decapods. Genetica 143, 195-205.

Baxter, D.A., Bittner, G.D., Brown, T.H., 1985. Quantal mechanism of long-term syanptic potentiation. Proc. Natl. Acad. Sci. U. S. A. 82, 5978-5982.

Bracken, H.D., De Grave, S., Felder, D., 2009. Phylogeny of the infraorder Caridea based on mitochondrial and nuclear genes (Crustacea: Decapoda). In: Martin, J.W., Crandall, K.A., Felder, D.L. (Eds.), Decapod Crustacean Phylogenetics 18. Taylor and Francis, Boca Raton, pp. 274-298.

Brown, A., Hauton, C., 2018. Ecotoxicological response to chalcopyrite exposure in a proxy for deep-sea hydrothermal vent shrimp: implications for seafloor massive sulphide mining. Chem. Ecol. 34, 391-396.

Brown, A., Thatje, S., 2014. Explaining bathymetric diversity patterns in marine benthic invertebrates and demersal fishes: physiological contributions to adaptation of life at depth. Biol. Rev. 89, 406-426.

Brown, A., Thatje, S., 2015. The effects of changing climate on faunal depth distributions determine winners and losers. Glob. Chang. Biol. 21, 173-180.

Brown, A., Thatje, S., 2018. NMDA receptor regulation is involved in the limitation of physiological tolerance to both low temperature and high hydrostatic pressure. Front. Mar. Sci. 5, 93.

Brown, A., Thatje, S., Hauton, C., 2017a. The effects of temperature and hydrostatic 
pressure on metal toxicity: insights into toxicity in the deep sea. Environ. Sci. Technol. 17, 10222-10231.

Brown, A., Thatje, S., Morris, J.P.M., Oliphant, A., Morgan, E.A., Hauton, C., Jones, D.O.B., Pond, D.W., 2017b. Metabolic costs imposed by hydrostatic pressure constrain bathymetric range in the lithodid crab Lithodes maja. J. Exp. Biol. 220, 3916-3926.

Calder, P.C., 2015. Functional roles of fatty acids and their effects on human health. J. Parenter. Enter. 39, 18S-32S.

Christie, W.W., 1982. Lipid Analysis: Isolation, Separation, Identification, and Structural Analysis of Lipids. Pergamon Press, Oxford.

Cottin, D., Shillito, B., Chertemps, T., Thatje, S., Leger, N., Ravaux, J., 2010. Comparison of heat-shock responses between the hydrothermal vent shrimp Rimicaris exoculate and the related coastal shrimp Palaemonetes varians. J. Exp. Mar. Biol. Ecol. 393, 9-16.

Cottin, D., Brown, A., Oliphant, A., Mestre, N.C., Ravaux, J., Shillito, B., Thatje, S., 2012. Sustained hydrostatic pressure tolerance of the shallow-water shrimp Palaemonetes varians at different temperatures: insights into the colonisation of the deep sea. Comp. Biochem. Phys. A 162, 357-363.

Davis, K.E., De Grave, S., Delmer, C., Wills, M.A., 2018. Freshwater transitions and symbioses shaped the evolution and extant diversity of caridean shrimps. Nat. Commun. Biol. 1, 16.

De Grave, S., Ashelby, C.W., 2013. A re-appraisal of the systematic status of selected genera in Palaemoninae (Crustacea: Decapoda: Palaemonidae). Zootaxa 3734 $331-344$.

Desbruyeres, D., Biscoito, M., Caprais, J.C., Colaço, A., Comtet, T., Crassous, P., Fouquet, Y., Khripounoff, A., Le Bris, N., Olu, K., Riso, R., Sarradin, P.M., Segonzac, M., Vangriesheim, A., 2001. Variations in deep-sea hydrothermal vent communities on the mid-Atlantic ridge near the Azores plateau. Deep-Sea Res. I 48, 1325-1346.

Downing, A.B., Wallace, G.T., Yancey, P.H., 2018. Organic osmolytes of amphipods from littoral to hadal zones: increases with depth in trimethylamine $\mathrm{N}$-oxide, scyllo-inositol and other potential pressure counteractants. Deep-Sea Res. I 138, 1-10.

Dumuis, A., Sebben, M., Haynes, L., Pin, J.-L., Bockaert, J., 1988. NMDA receptors activate the arachidonic cascade in striatal neurons. Nature 336, 68-70.

Endo, Y., Yamano, F., 2006. Diel vertical migration of Euphausia pacifica (Crustacea, Euphausiacea) in relation to molt and reproductive processes, and feeding activity. J. Oceanogr. 62, 693-703.

Folch, J., Lees, M., Stanley, G.H.S., 1957. A simple method for the isolation and purification of total lipides from animal tissue. J. Biol. Chem. 226, 497-509.

Freire, C.A., Onken, H., McNamara, J.C., 2008. A structure-function analysis of ion transport in crustacean gills and excretory organs. Comp. Biochem. Physiol. A 151 272-304.

Gibbs, A., Somero, G.N., 1989. Pressure adaptation of $\mathrm{Na}^{+} / \mathrm{K}^{+}$ATPase in gills of marine teleosts. J. Exp. Biol. 143, 475-492.

Gonzalez-Rey, M., Serafim, A., Company, R., Gomes, T., Bebianno, M.J., 2006. Detoxification mechanisms in shrimp: comparative approach between hydrothermal vent fields and estuarine environments. Mar. Environ. Res. 66, 35-37.

Gonzalez-Rey, M., Serafim, A., Company, R., Bebianno, M.J., 2007. Adaptation to metal toxicity: a comparison of hydrothermal vent and coastal shrimps. Mar. Ecol. 28, 100-107.

Guschina, I.A., Harwood, J.L., 2006. Mechanisms of temperature adaptation in poikoltherms. FEBS Lett. 580, 5477-5483.

Hazel, J.R., 1995. Thermal adaptation in biological membranes: is homeoviscous adaptation the explanation? Annu. Rev. Physiol. 57, 19-42.

Hazel, J.R., Williams, E.E., 1990. The role of alterations in membrane lipid composition in enabling physiological adaptation of organisms to their physical environment. Prog. Lipid Res. 29, 167-227.

Hernández-Ávila, I., Cambon-Bonavita, M.-A., Pradillon, F., 2015. Morphology of first zoeal stage of four genera of alvinocaridid shrimps from hydrothermal vents and cold seeps: implications for ecology, larval biology and phylogeny. PLoS One 10, e0144657.

Kaur, G., Cameron-Smith, D., Garg, M., Sinclair, A.J., 2011. Docosapentaenoic acid (22:5n-3): a review of its biological effects. Prog. Lipid Res. 50, 28-34.

Lahdes, E., Balogh, G., Fodor, E., Farkas, T., 2000. Adaptation of composition and biophysical properties of phospholipids to temperature by the crustacean, Gammarus spp. Lipids 35, 1093-1098.

Li, C.P., De Grave, S., Chan, T.Y., Lei, H.C., Chu, K.H., 2011. Molecular systematics of caridean shrimps based on five nuclear genes: implications for superfamily classification. Zool. Anz. 250, 270-279.

Liao, Y., De Grave, S., Ho, T.W., Ip, B.H.Y., Tsang, L.M., Chan, T.-Y., Chu, K.H., 2017. Molecular phylogeny of Pasiphaeidae (Crustacea, Decapoda, Caridea) reveals systematic incongruence of the current classification. Mol. Phylogenet. Evol. 115, $171-180$.

Lodish, H., Berk, A., Matsudaira, P., Kaiser, C.A., Krieger, M., Scott, M.P., Zipursky, S.L., Darnell, J., 2003. Molecular Cell Biology, $5^{\text {th }}$ edition. WH Freeman and Company, New York.

Lunina, A.A., Vereshchaka, A.L., 2014. Distribution of hydrothermal Alvinocaridid shrimps: effect of geomorphology and specialization to extreme biotopes. PLoS One 9, e92802.

Marcon, Y., Sahling, H., Borowski, C., dos Santos Ferreira, C., Thal, J., Bohrmann, G., 2013. Megafaunal distribution and assessment of total methane and sulfide consumption by mussel beds at Menez Gwen hydrothermal vent, based on geo-referenced photomosaics. Deep-Sea Res. I 75, 93-109.

Mestre, N.C., Brown, A., Thatje, S., 2013. Temperature and pressure tolerance of larvae of Crepidula fornicata suggest thermal limitation of bathymetric range. Mar. Biol. 160, 743-750.

Mestre, N.C., Cottin, D., Bettencourt, R., Colaço, A., Correia, S.P.C., Shillito, B., Thatje, S.,
Ravaux, J., 2015. Is the deep-sea crab Chaceon affinis able to induce a thermal stress response? Comp. Biochem. Physiol. A 181, 54-61.

Morris, J.P., Thatje, S., Cottin, D., Oliphant, A., Brown, A., Shillito, B., Ravaux, J., Hauton, C., 2015a. The potential for climate-driven bathymetric range shifts: sustained temperature and pressure exposures on a marine ectotherm, Palaemonetes varians. R. Soc. Open Sci. 2, 150472

Morris, J.P., Thatje, S., Ravaux, J., Shillito, B., Fernando, D., Hauton, C., 2015b. Acute combined pressure and temperature exposures on a shallow-water crustacean: novel insights into the stress response and high pressure neurological syndrome. Comp. Biochem. Physiol. A 181, 9-17.

Morris, J.P., Thatje, S., Ravaux, J., Shillito, B., Hauton, C., 2015c. Characterising multilevel effects of an acute pressure exposure on a shallow-water invertebrate: insights into the kinetics and hierarchy of the stress response. J. Exp. Biol. 218, 2594-2602.

Munro, C., Morris, J.P., Brown, A., Hauton, C., Thatje, S., 2015. The role of ontogeny in physiological tolerance: decreasing hydrostatic pressure tolerance with development in the northern stone crab Lithodes maja. Proc. R. Soc. B 282, 20150577.

Needleman, P., Turk, J., Jakschik, B.A., Morrison, A.R., Lefkowith, J.B., 1986. Arachidonic acid metabolism. Ann. Rev. Biochem. 55, 69-102.

New, P., Brown, A., Oliphant, A., Burchell, P., Smith, A., Thatje, S., 2014. The effects of temperature and pressure acclimation on the temperature and pressure tolerance of the shallow-water shrimp Palaemonetes varians. Mar. Biol. 161, 697-709.

Oliphant, A., Thatje, S., Brown, A., Morini, M., Ravaux, J., Shillito, B., 2011. Pressure tolerance of the shallow-water caridean shrimp Palaemonetes varians across its thermal tolerance window. J. Exp. Biol. 214, 1109-1117.

O'Neill, P.J., Jinks, R.N., Herzog, E.D., Battelle, B.-A., Kass, L., Renninger, G.H., Chamberlain, S.C., 1995. The morphology of the dorsal eye of the hydrothermal vent shrimp, Rimicaris exoculata. Vis. Neurosci. 12, 861-875.

Pallareti, L., Brown, A., Thatje, S., 2018. Variability in hydrostatic pressure tolerance between Palaemon species: implications for insights into the colonisation of the deep sea. J. Exp. Mar. Biol. Ecol. 503, 66-71.

Pond, D.W., Tarling, G.A., Mayor, D.J., 2014. Hydrostatic pressure and temperature effects on the membranes of a seasonally migrating marine copepod. PLoS One 9, e111043.

Pörtner, H.O., 2001. Climate change and temperature-dependent biogeography: oxygen limitation of thermal tolerance in animals. Naturwissenchaften 88, 137-146.

Pörtner, H.O., 2002. Climate variations and the physiological basis of temperature dependent biogeography: systemic to molecular hierarchy of thermal tolerance in animals. Comp. Biochem. Physiol. A 132, 739-761.

Ravaux, J., Gaill, F., Le Bris, N., Sarradin, P.M., Jollivet, D., Shillito, B., 2003. Heat-shock response and temperature resistance in the deep-sea vent shrimp Rimicaris exoculata. J. Exp. Biol. 206, 2345-2354.

Ravaux, J., Leger, N., Rabet, N., Morini, M., Zbinden, M., Thatje, S., Shillito, B., 2012. Adaptation to thermally variable environments: capacity for acclimation of thermal limit and heat shock response in the shrimp Palaemonetes varians. J. Comp. Physiol. B. 182, 899-907.

Ravaux, J., Hamel, G., Zbinden, M., Tasiemski, A.A., Boutet, I., Léger, N., Tanguy, A., Jollivet, D., Shillito, B., 2013. Thermal limit for metazoan life in question: In vivo heat tolerance of the Pompeii worm. PLoS One 8, E64074.

Ravaux, J., Leger, N., Rabet, N., Fourgous, C., Voland, G., Zbinden, M., Shillito, B., 2016. Plasticity and acquisition of the thermal tolerance (upper thermal limit and heat shock response) in the intertidal species Palaemon elegans. J. Exp. Mar. Biol. Ecol. 484, 39-45.

Rongers, D., Walsh, J.P., Sinclair, B.J., Stillman, J.H., 2012. Changes in extreme cold tolerance, membrane composition and cardiac transcriptome during the first day of thermal acclimation in the porcelain crab Petrolisthes cinctipes. J. Exp. Biol. 215, 1824-1836.

Sébert, P., 2010. Comparative High Pressure Biology. Science Publishers, Enfield.

Shillito, B., Jollivet, D., Sarradin, P.-M., Rodier, P., Lallier, F., Desbruyéres, D., Gaill, F., 2001. Temperature resistance of Hesiolyra bergi, a polychaetous annelid living on deep-sea vent smoker walls. Mar. Ecol. Prog. Ser. 216, 141-149.

Shillito, B., Le Bris, N., Hourdez, S., Ravaux, J., Cottin, D., Caprais, J.C., Jollivet, D., Gaill, F., 2006. Temperature resistance studies on the deep-sea vent shrimp Mirocaris fortunata. J. Exp. Biol. 209, 945-955.

Smith, F., Brown, A., Mestre, N.C., Reed, A.J., Thatje, S., 2013. Thermal adaptations in deep-sea hydrothermal vent and shallow-water shrimp. Deep-Sea Res. II 92, 234-239.

Stoffel, W., Bosio, A., 1997. Myelin glycolipids and their functions. Curr. Opin. Neurobiol. 7, 654-661.

Sun, S., Hui, M., Wang, M., Sha, Z., 2018a. The complete mitochondrial genome of the alvinocarid shrimp Shinkaicaris leurokolos (Decapoda, Caridea): insight into the mitochondrial genetic basis of deep-sea hydrothermal vent adaptation in the shrimp. Comp. Biochem. Physiol. D 25, 42-52.

Sun, S., Sha, Z., Wang, Y., 2018b. Phylogenetic position of Alvinocarididae (Crustacea: Decapoda: Caridea): New insights into the origin and evolutionary history of the hydrothermal vent alvinocarid shrimps. Deep-Sea Res. I 141, 93-105.

Waagner, D., Holmstrup, M., Bayley, M., Sørensen, J.G., 2013. Induced cold-tolerance mechanisms depend on the duration of acclimation in the chill-sensitive Folsomia candida (Collembola). J. Exp. Biol. 216, 1991-2000.

Yahagi, T., Watanabe, H., Ishibashi, J., Kojima, S., 2015. Genetic population structure of four hydrothermal vent shrimp species (Alvinocarididae) in the Okinawa trough, Northwest Pacific. Mar. Ecol. Prog. Ser. 529, 159-169.

Yamada, H., Yamazaki, Y., Koike, S., Hakozaki, M., Nagahora, N., Yuki, S., Yano, A., Tsurumi, K., Okumura, T., 2017. Lipids, fatty acids and hydroxy-fatty acids of Euphausia pacifica. Sci. Rep. 7, 9944.

Yancey, P.H., Siebenaller, J.F., 2015. Co-evolution of proteins and solutions: protein adaptation versus cytoprotective micromolecules and their roles in marine organ isms. J. Exp. Biol. 218, 1880-1896. 